\title{
Abnormally large magnetospheric electric field on 9 November 2004 and its effect on equatorial ionosphere around the world
}

\author{
R G Rastogi ${ }^{1}$, H Chandra ${ }^{1, *}$, Louis Condori ${ }^{2}$, M A Abdu ${ }^{3}$, B Reinisch ${ }^{4}$,

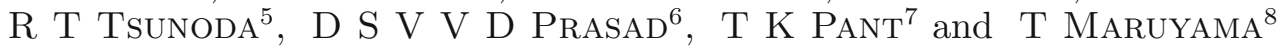 \\ ${ }^{1}$ Physical Research Laboratory, Ahmedabad 380 009, India. \\ 2 Jicamarca Radio Observatory, Jicamarca, Lima, Peru. \\ ${ }^{3}$ Instituto Nacionale de Pesquissas Espaciais, Sao Jose dos Campos, Brazil. \\ ${ }^{4}$ Center for Atmospheric Research, University of Massachussets, Lowell, USA. \\ ${ }^{5}$ Stanford Research Institute, Stanford, USA. \\ ${ }^{6}$ Department of Physics, Andhra University, Visakhapatnam, India. \\ ${ }^{7}$ Space Physics Laboratory, Thiruvananthapuram, India. \\ ${ }^{8}$ National Institute of Information and Communication Technology, Tokyo, Japan. \\ ${ }^{*}$ Corresponding author. e-mail: hchandra@prl.res.in
}

There was a solar event around 1850 UT on 9th November 2004, associated with an abnormally large solar wind flow pressure and large southward interplanetary magnetic field, causing an abnormally large prompt penetration electric field between 1850 and 2100 UT. Abnormally large vertical F-region drifts by Jicamarca backscatter radar were reported associated with the event. The F-region over Jicamarca, Peru (14-16 LT) and Sao Luis, Brazil (16-18 LT) was lifted upward, broken into two portions and the upper one was blown out of the range of the ionosonde. At Fortaleza, an off-equatorial station in Brazil, the F-region was also lifted up but later the $\mathrm{f}_{\mathrm{o}} \mathrm{F}_{2}$ increased due to the flow of ionization from upper layer blown up over the equatorial region. The F-region at Ascension Island (19-21 LT), an off-equatorial station, was lifted up without any deformations till 1915 LT but descended at 1930 LT due to reversal of electric field polarity. At Indian stations, Trivandrum and Waltair (00-02 LT), the F-region was pushed down and later disappeared as a consequence of enhanced westward ionospheric electric field in the night sector. The ionosonde did not receive any echo for a couple of hours till the next sunrise. The F-region at Kototaban (03-05 LT), Indonesia also disappeared after a rapid descend. At Kwajelien (06-08 LT) there was no equatorial type of sporadic-E at 07 to 09 LT due to the westward electric field.

\section{Introduction}

Day-to-day variability of the ionospherethermosphere during geomagnetic disturbed conditions is still not fully understood. The response over equatorial and low latitude ionosphere result from the disturbances in the electric fields and thermospheric dynamics that propagate from polar to equatorial latitudes. The interplanetary and polar electric fields promptly penetrate to equatorial latitudes as dawn-dusk electric fields during the onset and growth phases of a geomagnetic storm with time scales of the order of an hour to several hours. These are partially

Keywords. Equatorial ionosphere; space weather; geomagnetic storm. 
balanced by the development of a shielding layer in the inner magnetosphere (Vasyliunas 1972; Kelley et al. 1979). Rapidly changing polar electric fields penetrate to equatorial latitudes unaffected by shielding layer (Kikuchi et al. 1996). The prompt penetrating electric field is eastward on the dayside and westward during night side, therefore, it enhances the daytime eastward electric field. In the recovery phase of the storm, the electric field due to shielding layer penetrates to equatorial latitudes as an overshielding electric field with opposite polarity, westward during dayside and eastward during night side (Kelley et al. 1979). In addition to the prompt penetration electric fields, there are disturbance dynamo fields caused by the disturbed winds that produce longer-lasting dynamo electric field that affect the equatorial electrodynamics within a few hours from the onset of a storm and continue for several hours (Blanc and Richmond 1980). The disturbance dynamo is of opposite polarity (westward during day and eastward during night).

Electrodynamics plays an important role in the equatorial and low latitude ionosphere (Rastogi et al. 1972; Abdu 1997; Rastogi and Chandra 1999). The configuration of the northward magnetic field and zonal electric fields of dynamo origin give rise to special features of the ionosphere at low latitudes like equatorial electrojet, equatorial sporadic-E (Es-q), equatorial ionization anomaly and equatorial spread-F. On occasions, westward current flows during the daytime due to the electric field reversals known as counter electrojet. During periods of counter electrojet, the equatorial type of sporadic-E also disappears (Rastogi et al. 1971). The equatorial anomaly is related to the electrojet strength (electric field) and suppressed during the period of counter electrojet.

There have been numerous studies related to the geomagnetic storm effects in the density, composition and dynamics of the sub-auroral, middle and low latitude ionosphere and thermosphere (Rajaram et al. 1971; Kelley 1989; Rastogi 1989; Basu et al. 2001a, 2001b; Fuller-Rowell et al. 2002; Fejer 2004). Prompt penetration and disturbance dynamo electric fields, though of smaller magnitude, are the important sources of low latitude ionospheric electrodynamic disturbances. Sharp electric field perturbations with time scales typically shorter than about an hour are mostly due to the prompt penetration of magnetospheric electric fields to middle, low and equatorial latitudes (Fejer 2004). Quasi-period (DP2) magnetic field fluctuations with time scale of about half an hour to several hours at high latitudes and in the dayside of magnetic equator are signatures of convection electric fields controlled by IMF-Bz (Nishida 1968). Slower varying electric field disturbances with time scales of few hours to tens of hours are identified as ionospheric disturbance dynamo electric fields caused by enhanced energy deposition into the auroral ionosphere (e.g., Blanc and Richmond 1980).

Rastogi and Chandra (1974) first reported the association between the IMF-Bz and the ionospheric drifts near dip equator, a measure of the electric field in ionosphere. Rastogi and Patel (1975) suggested for the first time that the solar wind moving with a velocity $\mathrm{V}$, across the IMF$\mathrm{Bz}$ is equivalent to an interplanetary electric field (IEE), $\mathrm{E}=-\mathrm{V} \times \mathrm{Bz}$. On striking the magnetosphere, the electric field is transferred to polar electrojet region and then to the equatorial latitudes without any delay. They showed that a sudden and large turning of IMF-Bz to northward direction imposes westward electric field on the EEJ region causing a decrease of $\mathrm{H}$ field with a partial or full counter electrojet and the disappearance of Es-q. The transmission of the IEE to the equator was shown to be almost instantaneous, after taking into account the position of satellite recording IMF. This led to the disappearance of Es-q type of sporadic E layer during the daytime ionosphere and appearance of the equatorial spread $\mathrm{F}$ in the night-time ionosphere. Fejer et al. (1979) suggested that the rapid increases and decreases of the magnetospheric convection electric field can cause immediate effect at the magnetic equator.

With the availability of solar wind parameters recorded by instruments onboard satellites, several case studies are reported on the analyses of multiple ground-based observations in relation with satellite-based solar wind and IMF data during some of the prominent magnetic storms (Basu et al. 2001a, 2001b; Sastri et al. 2002; Kil and Paxton 2006; Mannucci et al. 2008).

\subsection{Motivation for the present analysis}

The space weather event of 9 November 2004 with sudden commencement at 1850 UT was unique with large electric field of magnetospheric origin. Fejer et al. (2007) reported vertical drifts of about $120 \mathrm{~m} / \mathrm{s}$ at $2000 \mathrm{UT}$ (1500 LT) on 9 November 2004 , the largest daytime value ever measured by the radar and associated with the main phase of the geomagnetic storm. They have described in detail the relations between the equatorial electrodynamics with the solar wind and IMF parameters. This was a major magnetic storm and studied by many researchers (Maruyama 2006; Mannucci et al. 2008; Yermolaev et al. 2008). The solar wind and the IMF parameters are examined together with the ground magnetic data and ionosonde data at equatorial latitudes in different longitude sectors. List 
Table 1. Observatories, coordinates and parameters used.

\begin{tabular}{llrrrl}
\hline Station & Code & Latitude $\left({ }^{\circ} \mathrm{N}\right)$ & Longitude $\left({ }^{\circ} \mathrm{E}\right)$ & Dip $\left({ }^{\circ} \mathrm{N}\right)$ & Parameters \\
\hline Huancayo & HUA & -12.1 & -75.3 & 0.9 & $\Delta H$ \\
Fuquene & FUQ & $5.5 \mathrm{~N}$ & -73.7 & 31.2 & $\Delta H$ \\
Addis Ababa & AAE & 9.0 & 38.8 & 1.3 & $\Delta H$ \\
Eilat & ELT & 29.7 & 35.0 & 44.1 & $\Delta H$ \\
Tirunelveli & TIR & 8.7 & 77.7 & 1.9 & $\Delta H$ \\
Alibag & ABG & 18.6 & 72.9 & 25.3 & $\Delta H$ \\
Muntilupa & MUT & 14.4 & 121.0 & 15.3 & $\Delta H$ \\
Davao & DAV & 7.1 & 125.6 & -1.2 & $\Delta H$ \\
Okinawa & OKI & 24.8 & 125.3 & 35.4 & $\Delta H$ \\
Yap & YAP & 9.5 & 138.0 & 3.6 & $\Delta H$ \\
Piura & PIU & -5.0 & -81.1 & 31.1 & $\Delta H$ \\
Jicamarca & & -12.1 & -75.3 & 0.9 & Drift, ionograms \\
Sao Luis & & -2.6 & -44.2 & -4.6 & Ionograms \\
Fortaleza & & -3.9 & -14.4 & -11.6 & Ionograms \\
Ascension Island & ASC & -8.0 & 76.5 & 1.6 & Ionograms \\
Thumba & TRD & 8.5 & 83.3 & 22.7 & Ionograms \\
Waltair & & 17.7 & 130.2 & 13.8 & Ionograms \\
SHAR & & 13.7 & 100.3 & -19.7 & Ionograms \\
Yamagawa & & 167 & 8.9 & Ionograms \\
Kototaban & KTB & -0.2 & & &
\end{tabular}

of stations along with the coordinates and dip are given in table 1.

\section{Results}

\subsection{Solar wind and magnetic field}

The 5-minute values of the parameters IMF-Bz, solar wind flow speed V, solar wind proton density, solar wind flow pressure and the resulting interplanetary electric field $\mathrm{E}(-\mathrm{V} \times \mathrm{Bz})$ are shown in figure 1(a). The $\mathrm{SYM} / \mathrm{H}$ index is also plotted in the figure and shows sudden commencement (SC) of the geomagnetic storm around $1850 \mathrm{UT}$ associated with the southward turning of IMF-Bz and sudden increase of solar wind velocity, proton density and the flow pressure. The IMF-Bz turned negative and remained southward between 1900 and 2050 UT reaching values of $-30 \mathrm{nT}$. The solar wind speed was about $625 \mathrm{~km} / \mathrm{s}$ before the SC and increased rapidly to $800 \mathrm{~km} / \mathrm{s}$. The electric field rose rapidly from $2 \mathrm{mV} / \mathrm{m}$ with values exceeding $20 \mathrm{mV} / \mathrm{m}$ after 1945 UT. The IMF-Bz turned northward again at 2050 UT reaching values of almost $40 \mathrm{nT}$ and as a consequence, the electric field dropped to about $-30 \mathrm{mV} / \mathrm{m}$. The proton density was less than $10 /$ cc but increased sharply around 19 UT to values of about $35 / \mathrm{cc}$. It decreased to less than $15 / \mathrm{cc}$ at $1930 \mathrm{UT}$ and then rose to another peak of $27 / \mathrm{cc}$ at 2030 UT before decreasing to less than 10/cc at 21 UT. Small peaks were seen later around
2145 UT and 2245 UT. The variation of the flow pressure is almost similar as there is no significant change in the flow velocity after 19 UT. The vertical F-region drift velocity, $\mathrm{V}_{\mathrm{z}} \mathrm{F}$ measured at Jicamarca is also plotted in figure 1(a) between 18 and 22 UT. The vertical drift velocity is almost zero untill 1850 UT. Upward velocity is seen from $1850 \mathrm{UT}$ and increases rapidly later to a peak value of $120 \mathrm{~m} / \mathrm{s}$ at $20 \mathrm{UT}$. The velocity is much greater than the usual $20-25 \mathrm{~m} / \mathrm{s}$ on normal days. The vertical velocity turned downward at 21 UT. Thus from 1850 UT to 21 UT electric field was abnormally large eastward and from 21 UT onward westward. Comparing with the interplanetary electric field variations there is a good correspondence.

The deviation in the geomagnetic $H$ component, $\Delta H$ at equatorial stations in different longitude sectors for the 4-hr interval (18-22 UT) are shown in figure $1(\mathrm{~b})$. The stations chosen are Huancayo (HUA) and Fuquene (FUQ) in American sector $\left(75^{\circ} \mathrm{W}\right)$; Addis Ababa (AAE) and Eilat (ELT) in African sector $\left(35-40^{\circ} \mathrm{E}\right)$; Tirunelveli (TIR) and Alibag (ABG) in the Indian sector $\left(75^{\circ} \mathrm{E}\right)$; Davao (DAV) and Muntilupa (MUT) $\left(121-125^{\circ} \mathrm{E}\right)$ and Yap (YAP) and Okinwa (OKI) $\left(125-138^{\circ} \mathrm{E}\right)$ in the Fareast. Out of the pairs of stations chosen, one is in the electrojet region and another away from the electrojet region. The difference between $\Delta H$ at an equatorial electrojet station and at the station away from the electrojet is considered as an index of the electrojet strength. From the variation of $\Delta H$ at HUA and FUQ, one can notice that 


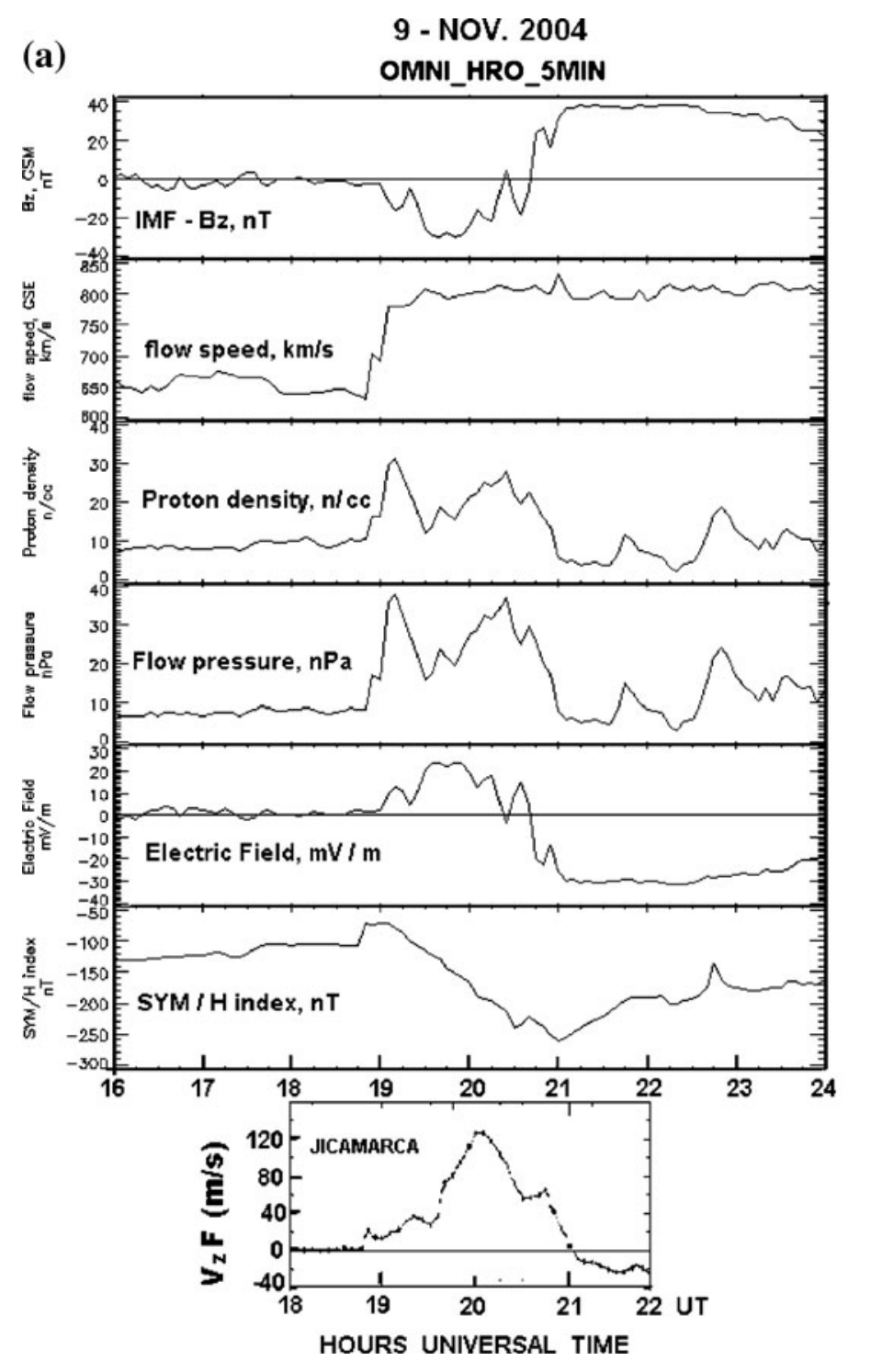

(b) 9 - NOV. 2004

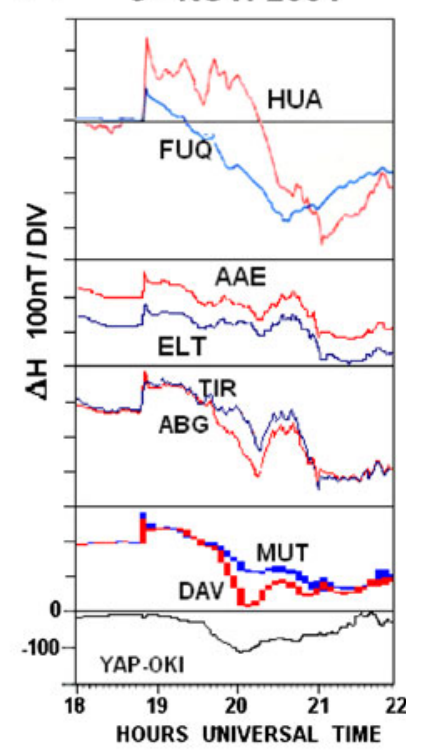

Figure 1. (a) Variations of the IMF-Bz, solar wind flow speed, solar wind proton density, solar wind flow pressure, computed electric field due to solar wind $(-\mathrm{V} \times \mathrm{Bz})$ and $\mathrm{Sym} / H$ index from 5 minute values for the period 16 to 24 UT on 9 November 2004. Also shown is the vertical drift at Jicamarca during 18-22 UT. (b) Variations of the deviations in geomagnetic $H$ component at an equatorial station and at a station away from magnetic equator at five longitude sectors for 18-22 UT on 9 November 2004.

up to about 1845 UT the values at the two stations are almost same implying very weak electrojet. Between 1850 and $2100 \mathrm{UT}$, the values are higher at HUA, implying normal electrojet. The difference is largest around 20 UT (15 LT) when electrojet is very strong (about $225 \mathrm{nT}$ ). Between 21 and 22 UT the values at HUA are lower than at FUQ, implying counter electrojet. In the African sector the values at AAE are almost similar to that at ELT throughout the period 18-22 UT, which is in the night hours (20-24 LT). Further east in the Indian sector, corresponding to night hours (23$03 \mathrm{LT})$ the values at TIR and ABG are similar up to 1940 UT. From 1940 to 2040 UT, the values are larger at ABG than at TIR, implying westward electric field. For the pair MUT and DAV, the values are higher at MUT than at DAV during 1940-21 UT or westward electric field. In the Japanese sector, values at OKI are higher than at YAP during the period 1900-2130 UT. The difference between YAP and OKI is also plotted in the figure showing the counter electrojet or westward electric field in the night hours with maximum around $20 \mathrm{UT}$.

The SC was noted around 1850 UT with amplitude greater than $200 \mathrm{nT}$ at HUA and about $100 \mathrm{nT}$ at FUQ. The amplitudes of SC are less in the African sector with values of about $60 \mathrm{nT}$. In the Indian sector, SC amplitude is about $100 \mathrm{nT}$ at TIR and $80 \mathrm{nT}$ at ABG. The SC amplitudes are about $60-70 \mathrm{nT}$ in the $120^{\circ} \mathrm{E}$ sector and about $25 \mathrm{nT}$ in the Japanese sector. 


\subsection{Ionosphere}

\subsubsection{Ionosphere: $75^{\circ} \mathrm{W}$}

To study the ionospheric effects of the storm at an equatorial station in the $75^{\circ} \mathrm{W}$ longitude sector, ionograms at Jicamarca are examined. Figure 2 shows the quarter hourly ionograms over Jicamarca from 1900 to 2145 UT (1400 to 1645 LT). The ionogram at 1400 LT shows the critical frequency of the F2 layer, $\mathrm{f}_{\mathrm{o}} \mathrm{F} 2$ around $14 \mathrm{MHz}$ and the minimum virtual height of the F2 layer around $350 \mathrm{~km}$. Subsequent ionograms show the base height of the F2 layer increasing steadily to $550 \mathrm{~km}$ at $1445 \mathrm{LT}, 700 \mathrm{~km}$ at $1500 \mathrm{LT}$ and rising further to $850 \mathrm{~km}$ at $1515 \mathrm{LT}, 1050 \mathrm{~km}$ at 1530 LT and finally rising to outside the range of the ionosonde. It also splits in two layers. The magnitude of the rise of the F2 layer is very unusual. The $\mathrm{f}_{\mathrm{o}} \mathrm{F} 2$ values also decrease to about $7 \mathrm{MHz}$ at $1600 \mathrm{LT}$ and later rise to $10 \mathrm{MHz}$ at 1645 LT. For comparison, the hourly ionograms at Jicamarca on 8 November 2004 are shown from 18 to $22 \mathrm{UT}$ ( 13 to $17 \mathrm{LT}$ ) in figure 3 . The $\mathrm{f}_{\mathrm{o}} \mathrm{F} 2$ values decrease steadily from $11 \mathrm{MHz}$ at $13 \mathrm{LT}$ to $8.5 \mathrm{MHz}$ at $17 \mathrm{LT}$ on this day. There are no drastic changes in the F-layer heights during this period. Thus the $\mathrm{f}_{\mathrm{o}} \mathrm{F} 2$ values in the afternoon of 9 November are comparatively smaller than on 8 November.
The variation with time of the F-layer critical frequency, $\mathrm{f}_{\mathrm{o}} \mathrm{F} 2$, height of maximum electron density, $h_{m} F$, and the minimum virtual height, $h^{\prime} F$ at Jicamarca from 11 to 18 LT on both the days (8 and 9 November 2004) are shown in figure 4. The F-layer vertical drift measured by the VHF radar at Jicamarca and the difference in the deviation in geomagnetic $H$ component, $\Delta H$ at Huancayo and at Piura for 9 November are also shown in the figure. Compared to 8 November, $\mathrm{f}_{\mathrm{o}} \mathrm{F} 2$ values are higher on 9 November before 15 LT and lower between 15 and $16 \mathrm{LT}$. Peak values of $14 \mathrm{MHz}$ are observed around 13-14 LT on 9 November as compared to $10 \mathrm{MHz}$ on 9 November. The height of maximum ionization, $\mathrm{h}_{\mathrm{m}} \mathrm{F}$ is slightly lower on 9 November untill 1445 LT. As the F-layer splits in two parts at this point there are two lines shown in the figure. The thin line shows the lower trace while thick line shows the upper part. Considering the upper part, the height shoots up to $850 \mathrm{~km}$ and then remains out of the range of ionosonde for half an hour. The lower part also shows increase in height for an hour and then falls below the values on 8 November. The variation of $h^{\prime} F$ on 9 November shows a rapid increase of $100 \mathrm{~km}$ in half an hour from 17 UT (12 LT) followed by steady decrease reaching the normal values around 2030 UT (1530 LT). However, there is no such increase in $\mathrm{h}_{\mathrm{m}} \mathrm{F}$ during this period. The unusual

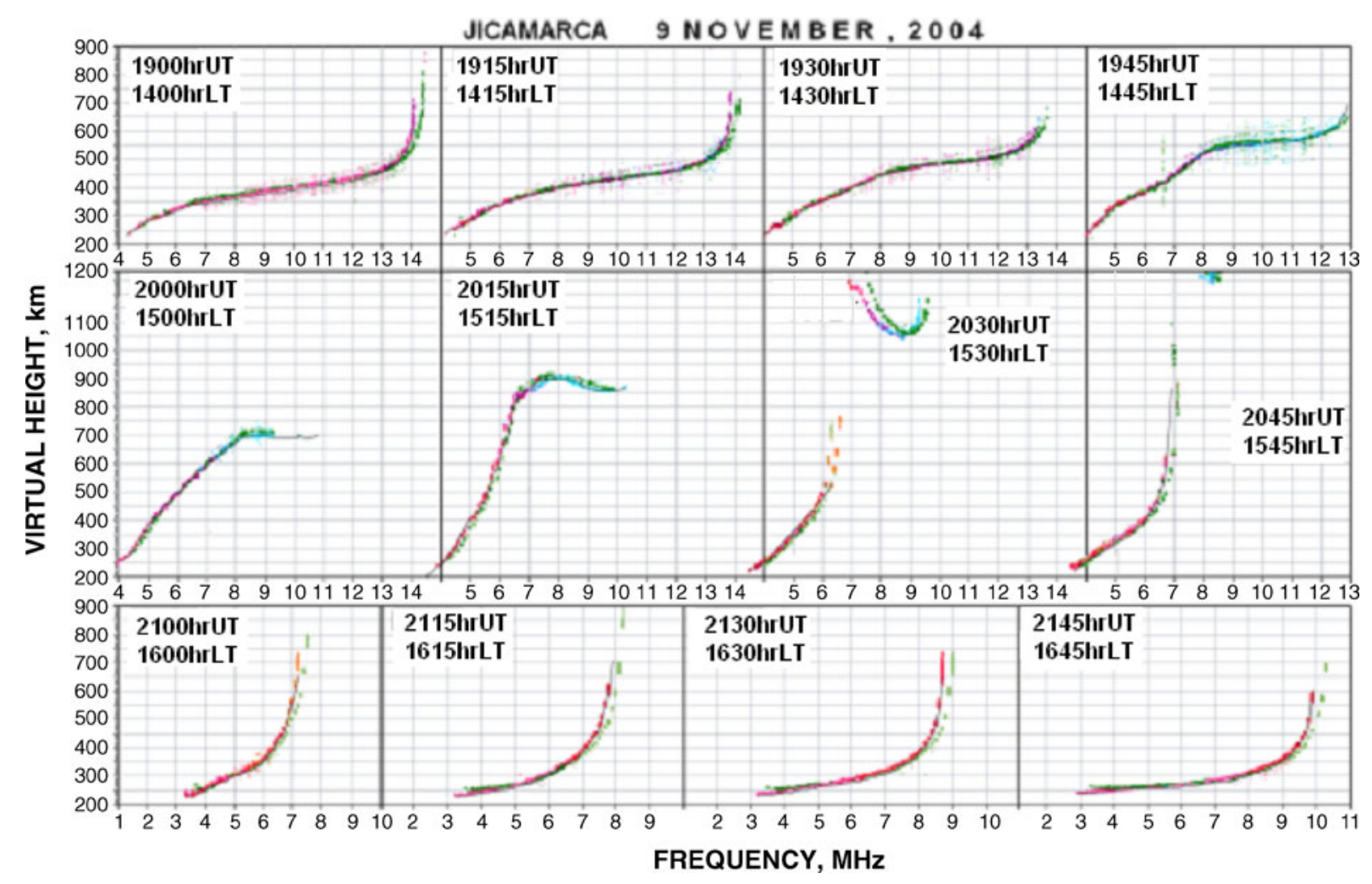

Figure 2. Selected ionograms over Jicamarca on 9 November 2004. 


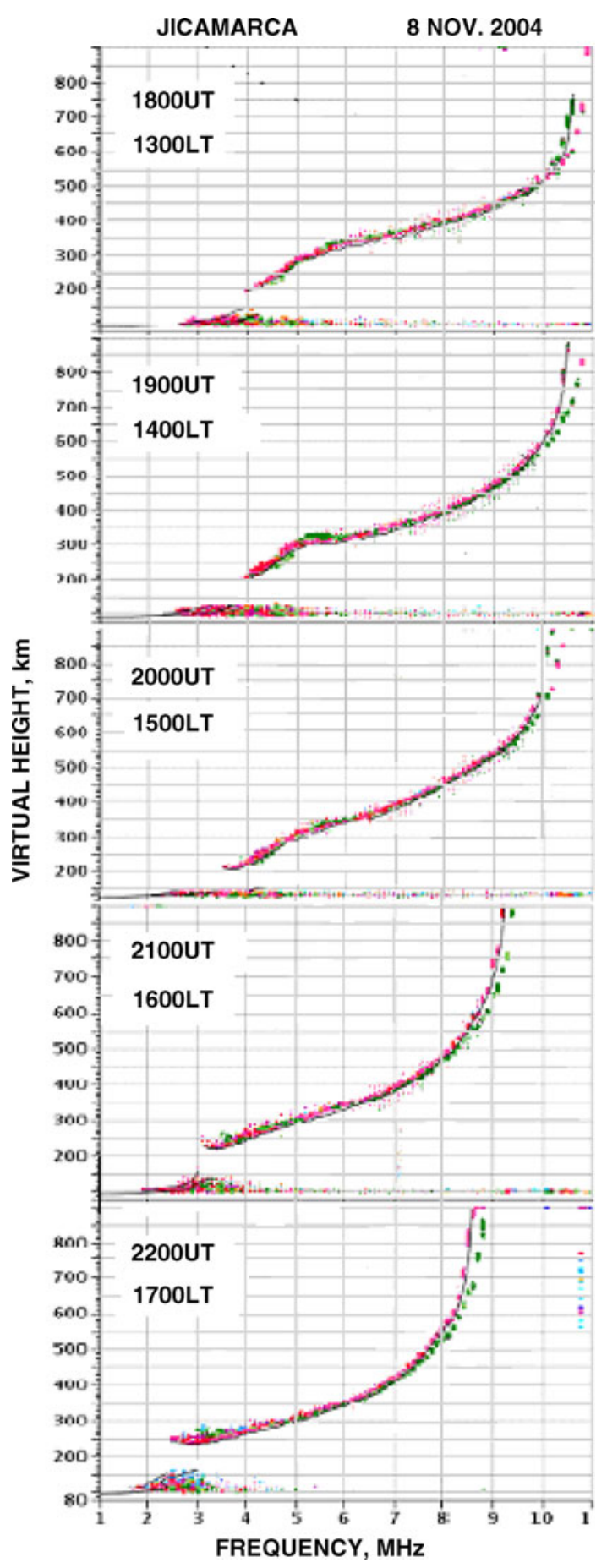

Figure 3. Selected ionograms over Jicamarca on 8 November 2004.

high values of $\mathrm{h}^{\prime} \mathrm{F}$ between 1700 and $1830 \mathrm{UT}$ (1200-1330 LT) on 9 November 2004 needs to be examined. The variation of the F-layer vertical drift on 9 November is most interesting with values less than $20 \mathrm{~m} / \mathrm{s}$ before $1845 \mathrm{UT}$ (1345 LT) and increasing to more than $120 \mathrm{~m} / \mathrm{s}$ at $2000 \mathrm{UT}$ (1500 LT). The vertical drift was downward from 2100 UT (1600 LT) onwards. Such large vertical drifts at Jicamarca were reported for the first time (Fejer et al. 2007). The variation of the difference

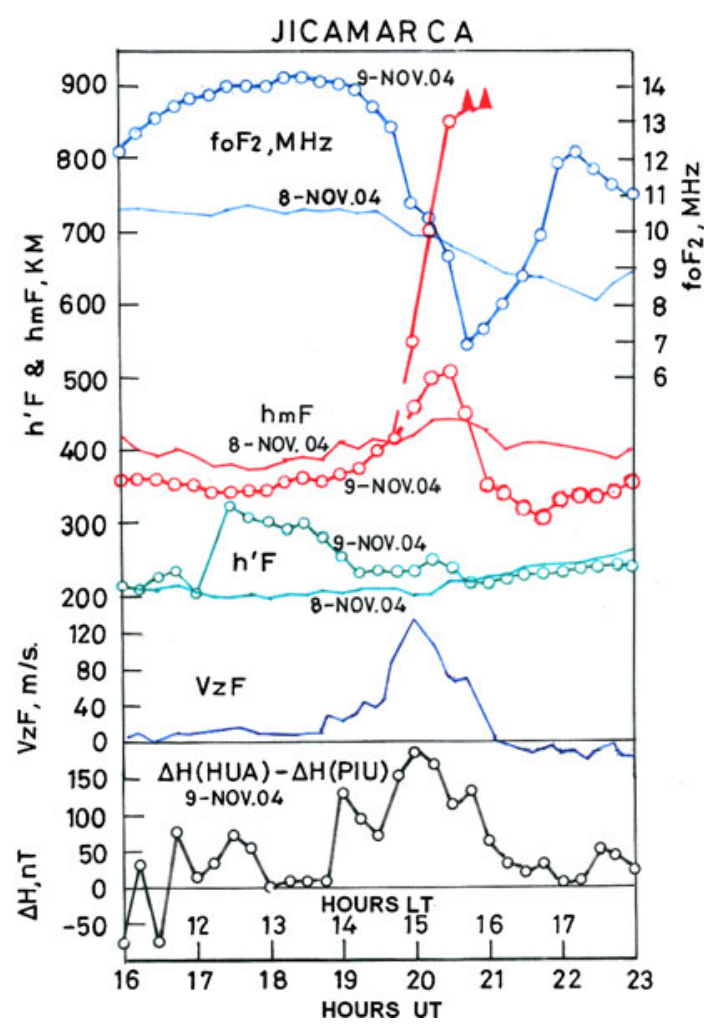

Figure 4. Variations of the ionospheric parameters, $\mathrm{f}_{\mathrm{o}} \mathrm{F} 2$, $\mathrm{h}_{\mathrm{m}} \mathrm{F}, \mathrm{h}^{\prime} \mathrm{F}$ at Jicamarca during $16-23$ UT on 8 and 9 November 2004. Also shown are the vertical drift measured at Jicamarca and the difference of the deviations in geomagnetic $H$ components at Huancayo and Piura.

in $\Delta H$ at Huancayo and Piura, an index of the electrojet shows negative values at 1600 and 1630 UT (1100 and $1130 \mathrm{LT}$ ), values less than $75 \mathrm{nT}$ untill 1800 UT (1300 LT), close to zero from 1745 to 1845 UT (1245 to 1345 LT) and then values exceeding $100 \mathrm{nT}$ for most part of time untill $1545 \mathrm{LT}$. The maximum value of about $175 \mathrm{nT}$ is at $2000 \mathrm{UT}$ (1500 LT) coinciding with the maximum upward drift velocity. Thus electric field was largest at 1500 LT giving rise to strong electrojet. The large electric field resulted in the large upward motion of F-layer and decrease of $f_{0} F 2$. The weak electrojet and low vertical drift before 1900 UT (1400 LT) gave rise to lower $h_{m} F$ and higher $f_{o} F 2$ values on 9 November (up to $4 \mathrm{MHz}$ ). The $\mathrm{h}^{\prime} \mathrm{F}$ values are significantly higher on 9 November between 17 and 19 UT (12 and 14 LT) compared to the values on 8 November.

\subsubsection{Ionosphere: $45^{\circ} \mathrm{W}$}

To study the effects in ionosphere in the longitude sector $45^{\circ} \mathrm{W}$, ionograms at Sao Luis $\left(44.2^{\circ} \mathrm{W}\right.$, dip $\left.4.6^{\circ} \mathrm{S}\right)$ and Fortaleza $\left(38.5^{\circ} \mathrm{W}\right.$, dip $\left.7^{\circ} \mathrm{S}\right)$ are examined. The ionograms at Sao Luis are shown in figure 5 . The rise in the F-layer and the splitting of F-region into two parts (2045 UT, 2115 UT) 


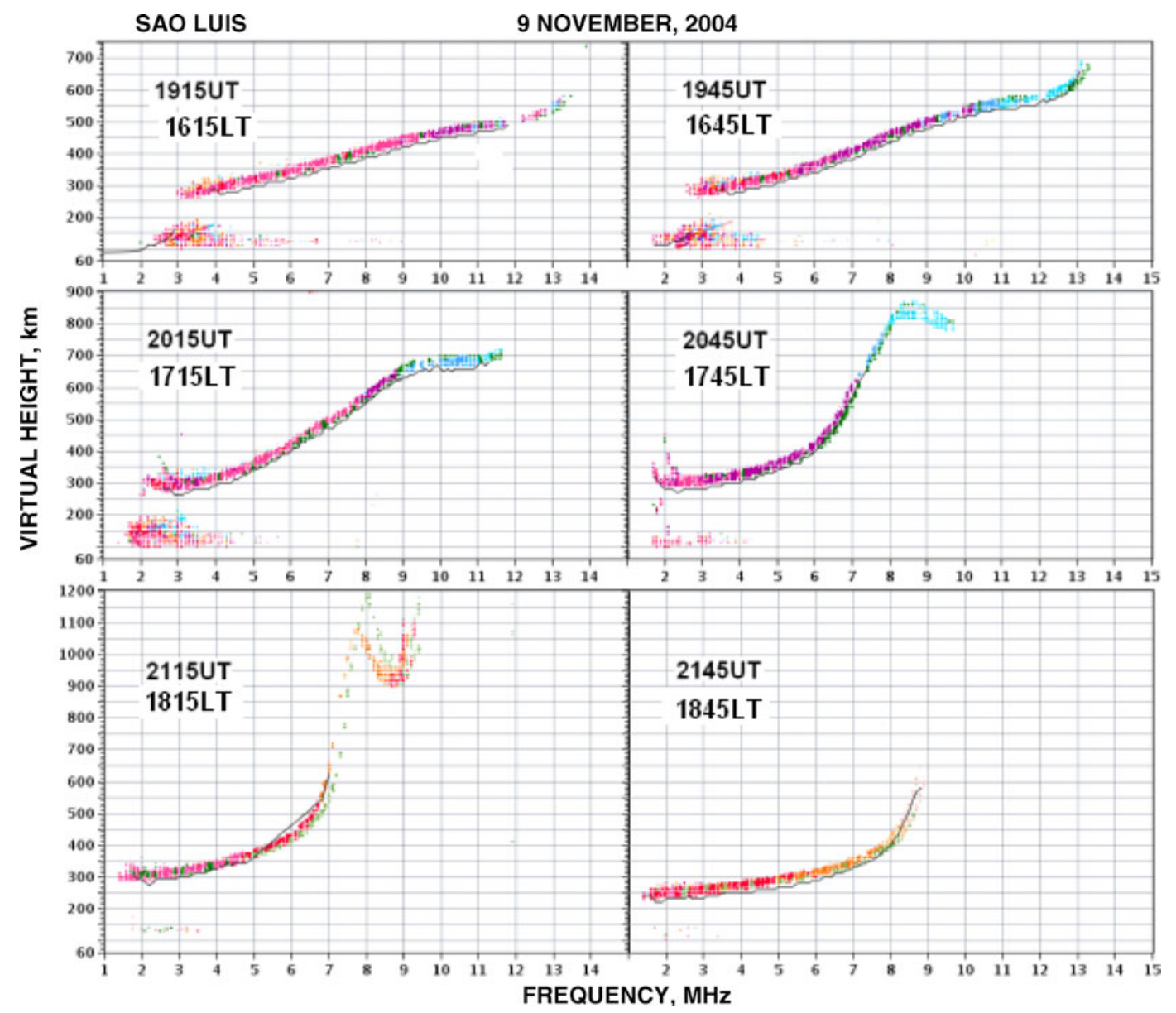

Figure 5. Selected ionograms over Sao Luis on 9 November 2004.

are again seen. The time variations of the F-layer parameters, $\mathrm{f}_{\mathrm{o}} \mathrm{F} 2, \mathrm{~h}_{\mathrm{m}} \mathrm{F}$ and $\mathrm{h}^{\prime} \mathrm{F}$ over Sao Luis on 9 November 2004 are shown in figure 6 . The results are similar to those observed at Jicamarca. $\mathrm{f}_{\mathrm{o}} \mathrm{F} 2$ values are close to $14 \mathrm{MHz}$ up to $1930 \mathrm{UT}$ (1630 LT), decrease rapidly to about $7 \mathrm{MHz}$ at 18 LT (21 UT) and increase again rapidly to values of about $14 \mathrm{MHz}$. The variation of $\mathrm{h}_{\mathrm{m}} \mathrm{F}$ shows increase from $1600 \mathrm{LT}$ and from $1945 \mathrm{UT}$ (1645 LT) splitting into two parts. The top layer reaches to altitude of $800 \mathrm{~km}$ at $2030 \mathrm{UT}$ (1730 LT) and moves outside the range of the instrument. The lower layer moves down to altitude of $350 \mathrm{~km}$. The variation of $h^{\prime} F$ is also similar to that observed at Jicamarca. There is an increase in $\mathrm{h}^{\prime} \mathrm{F}$ at $17 \mathrm{UT}$ (14 LT) and $\mathrm{h}^{\prime} \mathrm{F}$ values remain high untill $18 \mathrm{UT}$ (15 LT). The rapid rise of the F-layer and splitting into two portions and reaching to altitudes outside the range of the instrument occur at same UT at the two locations.

The ionograms at Fortaleza (at the edge of EEJ) are shown in figure 7 . The rise in F-layer peak height and decrease in $\mathrm{f}_{\mathrm{o}} \mathrm{F} 2$ around $2100 \mathrm{UT}$ (1800 LT) are noted but it does not go outside the range of ionosonde. The minimum value of $f_{o} F 2$

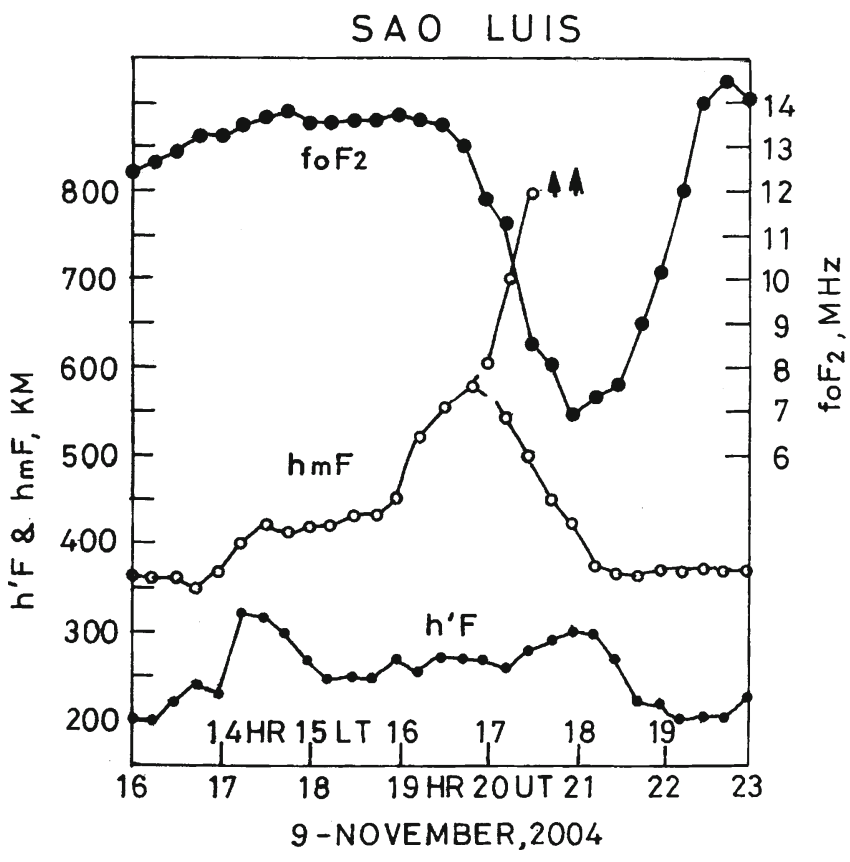

Figure 6. Variations of the ionospheric parameters $f_{0} F 2$, $\mathrm{h}_{\mathrm{m}} \mathrm{F}, \mathrm{h}^{\prime} \mathrm{F}$ during 16 to $23 \mathrm{UT}$ over Sao Luis on 9 November 2004 . 
FORTALEZA

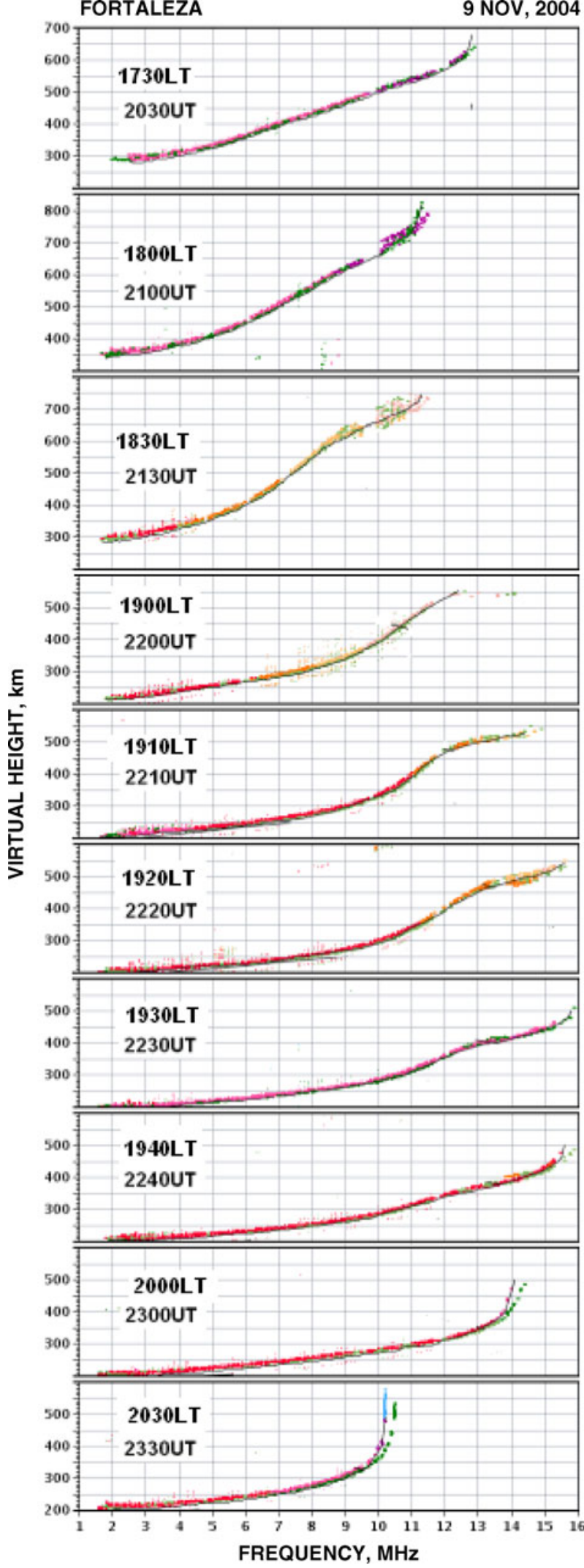

Figure 7. Selected ionograms over Fortaleza on 9 November 2004. (around $2100 \mathrm{UT}$ ) is close to $11 \mathrm{MHz}$ compared to less than $7 \mathrm{MHz}$ at Sao Luis. Large values of $\mathrm{f}_{\mathrm{o}} \mathrm{F} 2$ are seen around $2230 \mathrm{UT}$ (1930 LT) associated with the strong ionization anomaly due to large vertical upward drift and very high altitudes of F-layer.

\subsubsection{Ionosphere: $14^{\circ} \mathrm{W}$}

Further east at Ascension Island $\left(14.4^{\circ} \mathrm{W}\right.$, dip $\left.11.6^{\circ} \mathrm{S}\right)$ the event is in the evening hours. The ionograms in figure 8 show F-layer $\left(\mathrm{h}^{\prime} \mathrm{F}\right)$ rising from $250 \mathrm{~km}$ at $19 \mathrm{UT}$ (18 LT) to more than $400 \mathrm{~km}$ at 2015 UT (1915 LT). It descends rapidly to $300 \mathrm{~km}$ at 2030 UT (1930 LT).

\subsubsection{Ionosphere: $75^{\circ} \mathrm{E}$}

In the Indian longitude region, the ionograms at Thumba, close to dip equator for the night of 8-9 November are shown in figure $9(\mathrm{a})$. The ionogram at 2300 LT (18 UT) is normal with no spread-F and $\mathrm{h}^{\prime} \mathrm{F}$ around $250 \mathrm{~km}$. The ionogram for $1900 \mathrm{UT}$ (0000 LT) shows range spread with $\mathrm{h}^{\prime} \mathrm{F}$ of $300 \mathrm{~km}$. Subsequent ionograms at 1930 UT (0030 LT) and 2000 UT (0100 LT) show fully developed spread-F. At $0130 \mathrm{LT}, \mathrm{h}^{\prime} \mathrm{F}$ is lower than $300 \mathrm{~km}$ and spread-F is weaker. By 2130 UT (0230 LT), spread-F has disappeared and $\mathrm{h}^{\prime} \mathrm{F}$ is only $220 \mathrm{~km}$. The critical frequency of the F-layer is less than $4 \mathrm{MHz}$ from 1800 to 2200 UT (2300 to 0300 LT) but drops afterwards with values of just above $2 \mathrm{MHz}$ at 2330 and 0000 UT (0430 and 0500 LT).

The ionograms at Thumba for the night of 10 November are shown in figure 9(b). There is no spread-F as seen in ionograms from 1900 to 2045 UT (0000 to 0145 LT). The height of the layer $\left(\mathrm{h}^{\prime} \mathrm{F}\right)$ decreased steadily from about $220 \mathrm{~km}$ to less than $200 \mathrm{~km}$ at 2015 UT (0115 LT). The critical frequency also decreased from about $8 \mathrm{MHz}$ at $1900 \mathrm{UT}$ (0000 LT) to about $2 \mathrm{MHz}$ at $2045 \mathrm{UT}$ (0145 LT). No echo was seen at 2100 and 2115 UT (0200 and 0215 LT). Echoes were seen again from $2130 \mathrm{UT}$ (0230 LT) and the critical frequency also increases to $2.8 \mathrm{MHz}$ at $2200 \mathrm{UT}$ (0300 LT). There is decrease in the critical frequency later on and echoes disappear again from 2300 to $0000 \mathrm{UT}$ (0400-0500 LT). Fresh ionization is seen following the layer sunrise from 0015 UT (0515 LT) onwards. An examination of the height of maximum ionization, $\mathrm{hmF}$ and the critical frequency, $\mathrm{f}_{\mathrm{o}} \mathrm{F} 2$ at Thumba during the night of 9-10 November showed layer peak height decreases steadily from $365 \mathrm{~km}$ at $02 \mathrm{UT}$ (21 LT) to $280 \mathrm{~km}$ at $04 \mathrm{UT}$ (23 LT) and during this time $\mathrm{f}_{\mathrm{o}} \mathrm{F} 2$ increased from 9 to $11.5 \mathrm{MHz}$. There was a minor increase in the layer peak height from 18 UT (23 LT) to 19 UT (00 LT) and later it decreases untill 2045 UT 


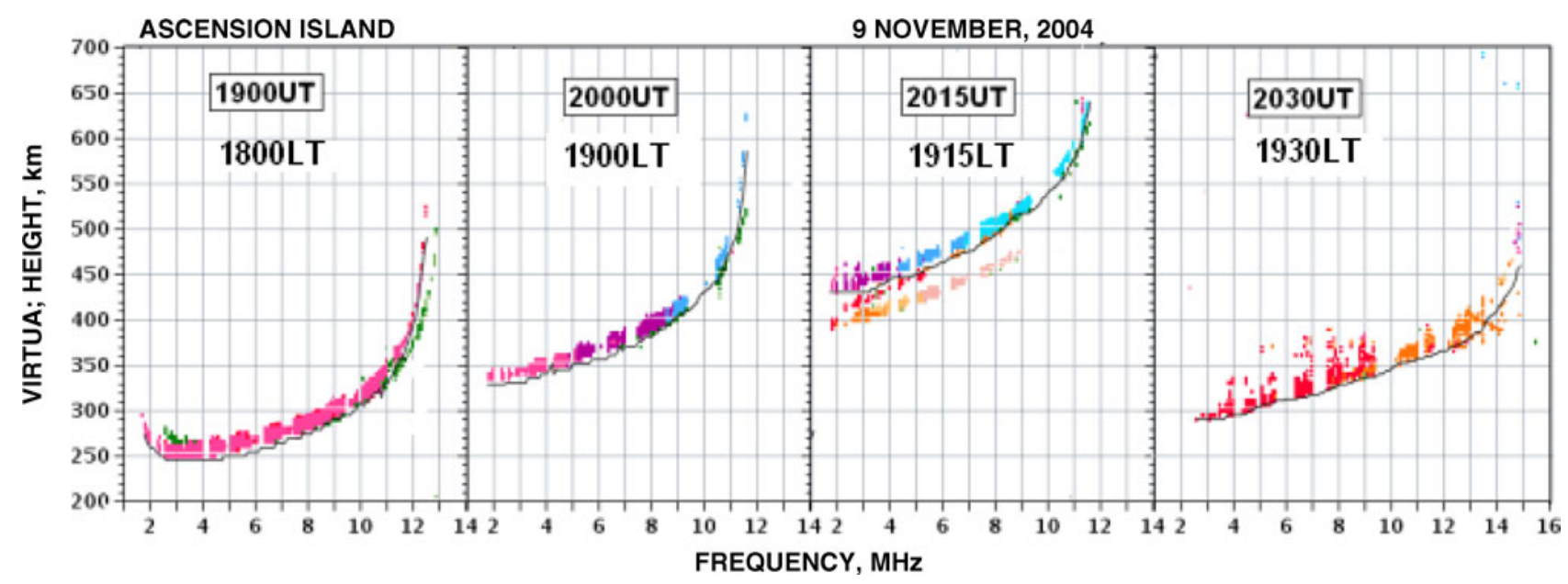

Figure 8. Selected ionograms over Ascension Island on 9 November 2004.

THUMBA

8 - 9 NOVEMBER, 2004



THUMBA

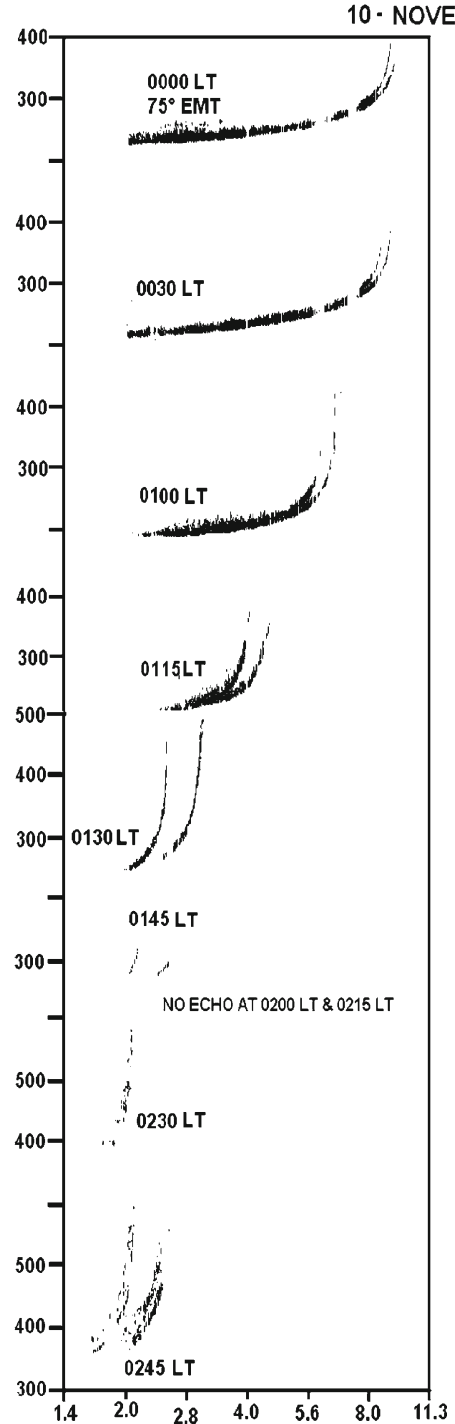

(b)

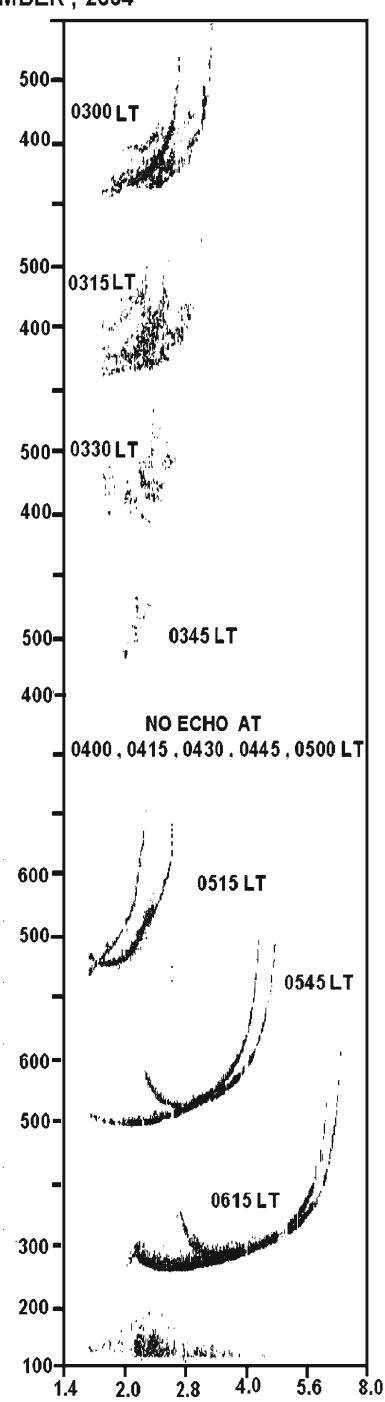

FREQUENCY, MHZ

Figure 9. Selected ionograms over Thumba (a) on 9 November 2004 and (b) on 10 November 2004. 
(0145 LT). During this descend of the layer peak, $\mathrm{f}_{\mathrm{o}} \mathrm{F} 2$ decreases fast and there are no echoes between 2100 and 2130 UT (0200 and 0230 LT) and again from 2300 to 0000 UT (0400-0500 LT). Thus as a consequence of the unusually large westward electric field during the local post midnight hours of 9 November 2004, the F-layer remained at lower altitude (less than $200 \mathrm{~km}$ at $0100 \mathrm{LT}$ ) and there was absence of spread-F.

The ionograms over SHAR, an off-equatorial station in India, in the early hours of 10 November are shown in figure 10. The ionogram at 1915 UT (0015 LT) shows clean F-region traces with no spread-F. Strong flat type of sporadic-E is seen with multiple echoes (six). F-layer traces with two multiples are seen above the blanketing frequency (about $3 \mathrm{MHz}$ ). There are two additional traces slightly above the E-layer traces up to about $3 \mathrm{MHz}$. These are likely due to the off-vertical echoes appearing at a slightly higher range and marked as slant echoes in the ionogram. The ionogram at 1945 UT (0045 LT) shows similar multiple echoes with slant traces from sporadic-E. The critical frequency of the F-layer, $\mathrm{f}_{\mathrm{O}} \mathrm{F} 2$, has decreased little. At 2015 UT (0115 LT), one can notice reduced number of multiple echoes from sporadic$\mathrm{E}$ but some patchy nature. The $\mathrm{f}_{\mathrm{o}} \mathrm{F} 2$ has further decreased. The ionogram at 2100 UT (0200 LT) shows further decrease in $\mathrm{f}_{\mathrm{o}} \mathrm{F} 2$ and four multiple echoes of sporadic-E. The F-region trace is hardly visible at $2115 \mathrm{UT}$ (0215 LT) and three multiple echoes of sporadic-E are seen. There is no F-region trace at $2200 \mathrm{UT}$ (0300 LT). The ionogram at $2230 \mathrm{UT}$ (0330 LT) shows enhanced sporadic-E with six multiple echoes. At $2300 \mathrm{UT}$ (0400 LT) one can see sporadic-E around $130 \mathrm{~km}$ and faint echoes from F-region at $600 \mathrm{~km}$ (virtual height). At 2315 UT (0415 LT) very weak echoes from sporadic-E are seen around $140 \mathrm{~km}$ and faint echo from F-layer at virtual height of $670 \mathrm{~km}$. At 2330 UT (0430 LT) there is no echo from F-region but sporadic-E is seen around $115 \mathrm{~km}$. There are no echoes at 2345, 0000 and $0015 \mathrm{UT}$ (0445, 0500 and 0515 LT). At 0030 UT (0530 LT) there are echoes from F-region above $450 \mathrm{~km}$ but these are from fresh ionization after the layer sunrise. Thus strong blanketing type sporadic-E with multiple echoes is seen at SHAR lasting for more than 3 hours.

The ionograms at Waltair, further northeast of SHAR, show similar strong sporadic-E (figure 11). The ionogram at 2000 UT (0100 LT) shows sporadic-E with three multiples. A sporadic-E trace just above the normal trace is likely the off-vertical slant trace. One can see multiple sporadic-E traces in ionograms at 2030, 2045 and 2100 UT (0130, 0145 and $0200 \mathrm{LT}$ ) with decreasing $\mathrm{f}_{\mathrm{o}} \mathrm{F}_{2}$. The ionograms at 2130, 2230 and 2245 UT (0230, 0330 and 0345 LT) show $4-5$ multiples of sporadic-E with no trace from F-region. There are no echoes from 2300 to 0015 UT (0400-0515 LT). F-region traces appear at 030n UT (0530 LT) around $450 \mathrm{~km}$ after the layer sunrise.

The occurrence of sporadic-E at low latitudes in India is highest during J-solstices both during daytime and night-time (Chandra and Rastogi 1974). The strong sporadic-E seen during the night of 10 November 2004 appears to be associated with the unusual large westward electric field imposed in the equatorial region in the Indian sector. The absence of F-region in ionograms at Thumba was also shown to occur with maximum frequency during J-solstices of low sunspot years (Chandra and Rastogi 1971).

\subsubsection{Ionosphere: $130^{\circ} \mathrm{E}$}

In the far-east, selected ionograms at Kototaban during the night of 9-10 November 2004 are shown in figure 12. At 1900 UT (0200 LT) weak spread-F is noted. Subsequent ionograms show F-layer descending from $270 \mathrm{~km}$ at $1900 \mathrm{UT}$ (0200 LT) to $200 \mathrm{~km}$ at $2000 \mathrm{UT}$ (0300 LT) and at the same time sporadic-E is seen from 1915 UT (0215 LT) onwards. F-layer traces become weak in ionograms from 2030 to 2130 UT (0330-0430 LT) and disappear at 2145 UT (0445 LT). However, sporadic$\mathrm{E}$ is present. There are no echoes at $2200-2230 \mathrm{UT}$ (0500-0530 LT). F-layer echo appears at 2245 UT (0545 LT) but after the layer sunrise above $300 \mathrm{~km}$.

Examination of ionograms at Yamagawa during the nights of 8 and 9 November 2004 showed clear F-region traces with F-layer descending from $300 \mathrm{~km}$ to about $230 \mathrm{~km}$ between 1800 and 2020 UT (0300-0530 LT) on 8 November 2004. The critical frequency decreases from 6.0 to $5.5 \mathrm{MHz}$. On 9 November 2004, the F-layer traces are clear but the critical frequencies are much lower than on 8 November 2004. The layer descends much faster during the night of 9 November 2004 to $200 \mathrm{~km}$ at 0400 LT (1900 UT). Sporadic-E traces with a multiple are seen from 2000 UT (0500 LT).

\subsubsection{Ionosphere: $16^{\circ}{ }^{\circ} \mathrm{E}$}

The ionograms at Kwajalein for 8 and 9 November 2004 are shown in figure 13. At 12 UT (23 LT) on 8 November 2004, clear F-layer trace with high multiples are noted with layer base height around $285 \mathrm{~km}$. High multiples are usually seen in the postsunset period with F-layer rising. Rapid rise of the F-layer is seen in subsequent hourly ionograms of 13 to 15 UT (00 to $02 \mathrm{LT}$ ). Spread-F starts developing near the base of F-layer at 14 UT (01 LT) and is fully developed at $15-16$ UT (02-03 LT). The layer starts descending (17-18 UT or 04-05 LT) 
SRI HARIKOTA 10 NOVEMBER, 2004
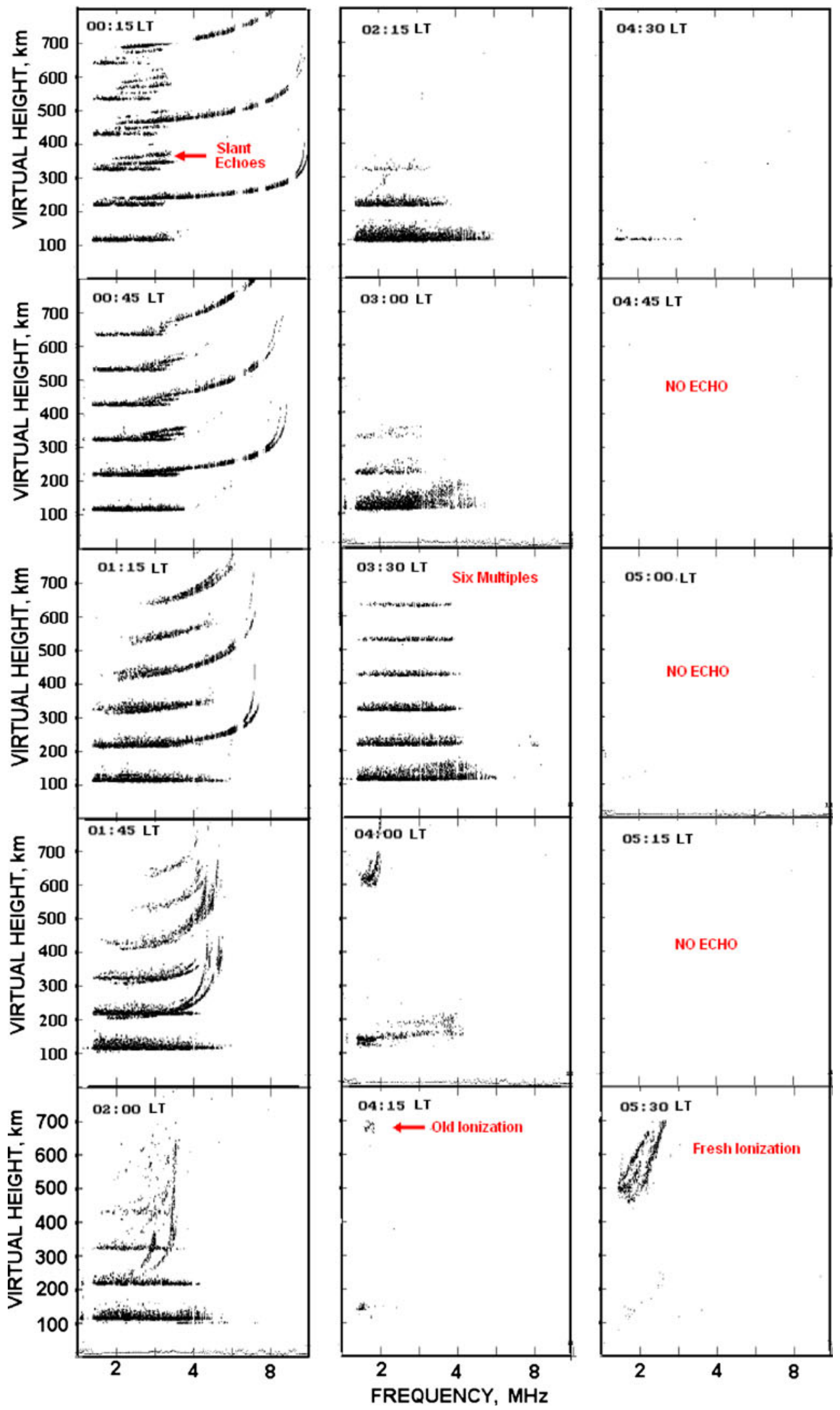

Figure 10. Selected ionograms over Sri Harikota on 10 November 2004. 


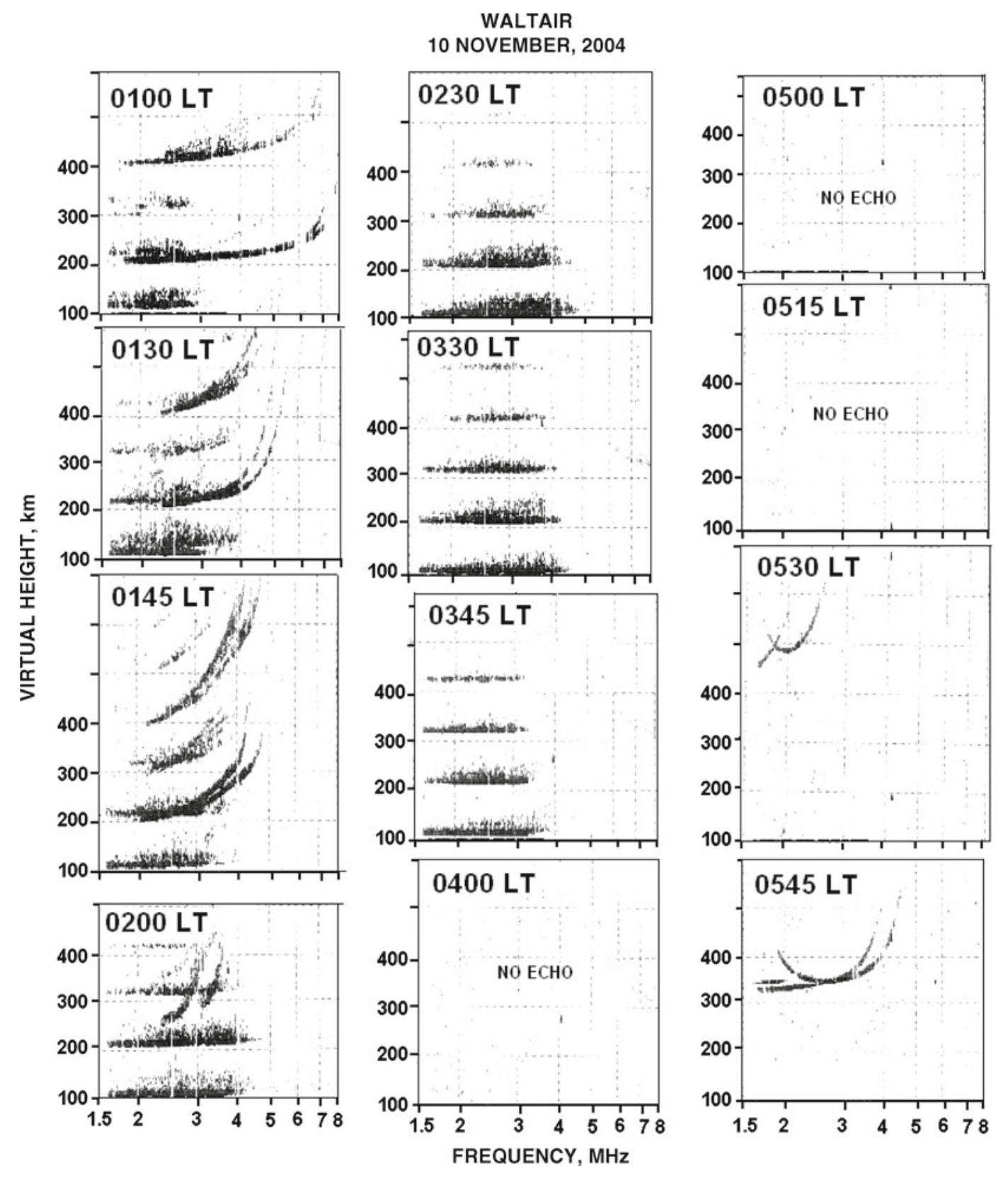

Figure 11. Selected ionograms over Waltair on 10 November 2004.

and fresh ionization is seen at $19 \mathrm{UT}$ (06 LT). The ionograms at $20 \mathrm{UT}$ (07 LT) show development of equatorial type sporadic-E indicating the electric field reversal to eastward. The ionograms on 9 November 2004 show almost clear F-layer trace at 12 UT (23 LT). Fully developed spread-F is seen in subsequent ionograms of 13-18 UT (00-05 LT). The F-layer height is lower than on 8 November 2004. Spread-F is seen only above $5 \mathrm{MHz}$ at $19 \mathrm{UT}$ (06 LT) and near the critical frequencies at $20 \mathrm{UT}$ (07 LT). Thus spread-F persists even after the sunrise. There is no equatorial type of sporadic-E seen at hourly ionograms of 20 to 22 UT (07-09 LT) indicating the electric field is still westward. As a consequence, there will not be vertical ExB upward plasma drift and no ionization anomaly. The very high value of the critical frequency of F-layer at 22 UT (09 LT) on 9 November 2004 indicates that there is no fountain effect.

\section{Discussion}

Several case studies have been made in recent years to study the equatorial ionospheric response to space weather events. Abdu et al. (2007) described the ionospheric responses to the major magnetic storm disturbances of October 2003 in Brazilian and Japanese-Asian longitude sectors. Prompt penetration of polar cap electric fields produced 


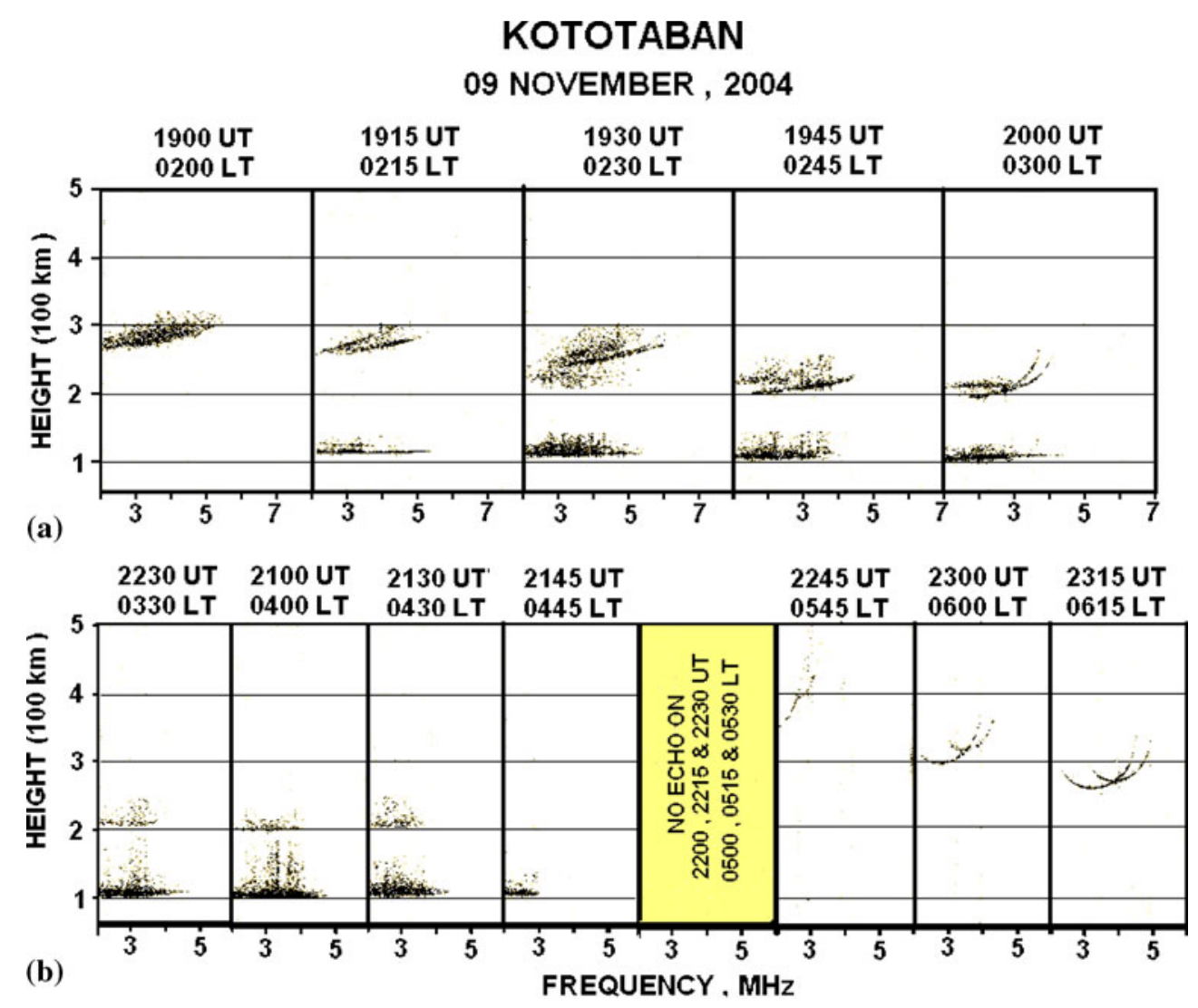

Figure 12. Selected ionograms over Kototaban on 9 November 2004.

large F-region plasma uplift on the dayside and downward on the night-side. Later Abdu et al. (2008) described striking difference in the intensity of prompt penetration electric field over Jicamarca and eastern Brazil sectors, and attributed effects arising from the particle precipitation in the South Atlantic anomaly region.

Veenadhari et al. (2010) described the penetration of magnetospheric electric fields to the magnetic equator during the magnetic storms of 31 March 2001 and 6 November 2001. They reported an enhancement of EIA during the main phase and its reduction during the recovery phase of the storm. Maruyama et al. (2005) studied the effect of March 2001 storm during the daytime and night-time ionosphere and have discussed the relative importance of prompt penetration and disturbance dynamic effects. De Jesus et al. (2010) have described the effect of the intense of geomagnetic storm of 14 December 2006 on the ionospheric F-region in the South American sector and reported unusual uplifting of the F-region during the pre-reversal enhancement due to the prompt penetration of the electric field.

Tulasi Ram et al. (2008) described multiinstrumental (ground-based and satellite-borne) and multi-station study of the ionosphere during five geomagnetic storms during 2004-2006. Bagia et al. (2011) have recently reported the response of the equatorial and low latitude ionospherethermosphere to the geomagnetic storm of 15 May 2005 from observations in the longitude sectors of $70^{\circ}-78^{\circ} \mathrm{E}$ and $270^{\circ}-288^{\circ} \mathrm{E}$ based on GPS observations. Dashora and Pandey (2007) studied the TEC near the anomaly crest in the Indian region recorded by a GPS receiver at Udaipur and attributed the reduced TEC following the storm by weakened electric field due to disturbance dynamo.

The space weather event of November 2004 has been studied by Fejer et al. (2007) using Jicamarca VHF radar, magnetometers in Peruvian (Jicamarca and Piura) and Pacific (Yap and Okinawa) regions and ionosonde data from Sao Luis in Brazil. Prompt penetration electric field of about $3 \mathrm{mV} / \mathrm{m}$, highest ever was recorded at Jicamarca during the main phase of the storm on November 9, 2004. Fejer et al. (2007) pointed that

- Following the SC at 1850 UT on November 9, upward drift increased reaching a value of about $120 \mathrm{~m} / \mathrm{s}$ around $2000 \mathrm{UT}$. The magnetometer data from Pacific region also showed exceptionally large westward current perturbation peaking around same time.

- Equatorial electric field and magnetic field decreased rapidly from about 2100 UT. 




Figure 13. Selected ionograms over Kwajalien on 8 and 9 November 2004.

Relatively large downward drift was observed from about 2100 to 0130 UT but magnetometer data was of quiet day pattern except for rapid perturbations. This indicated that while the initial decrease of drift was due to prompt penetration, longer lasting downward drifts were mainly due to the disturbance dynamo fields.

- Large disturbances were again seen between 0130 and 0700 UT both in the Pacific and Peruvian 
regions. The drifts over Jicamarca were predominantly upward except for when rapid changes in solar wind electric field was seen. The perturbations in magnetic field were of opposite polarity due to the fact that prompt penetration electric field change polarity around 0000-0100 UT.

- Large upward drift and westward current perturbations between 0400 and $0700 \mathrm{UT}$, a period of steady solar wind and reconnection electric field and decreasing Dst index indicated that except for brief periods of rapid changes in either solar wind and magnetosphere drivers, equatorial prompt penetration electric fields were either absent or smaller than the disturbance dynamo field.

- Between 0700 and 0900 UT large and shortlived velocity perturbations when solar wind electric field and polar cap potentials were large and steady but with large variations in ASY-H indicated overshielding electric fields following a weakening of ring current.

Fejer et al. (2007) concluded that during the main phase of the November 9, 2004 storm event, the prompt penetration electric field (eastward) had a life time of about one hour but not proportional to solar wind electric field. Rapid decrease of solar wind and polar cap potential after the storm resulted in equatorial westward electric field lasting for about 4 hours, which were mainly due to disturbance dynamo. Large magnitude short-lived prompt penetration electric fields and long lasting disturbance dynamo electric fields were observed in the night-side over Jicamarca and in the dayside in the Pacific during 10 November 2004. In this case, disturbance dynamo fields largely dominated.

Thus the large prompt penetration electric field between 19 and 21 UT resulted in large uplift of F-layer at Peruvian and Brazilian longitudes, broken into two parts and upper part blown out of the range of ionosonde. The local times at the two stations were $14-16 \mathrm{~h}$ and $16-18 \mathrm{~h}$. At Ascension Island, the F-layer rose between 1900 and 2015 UT (1800 and 1915 LT) but descended rapidly at 2030 UT (1930 LT) as the electric field reversal occurs around this time. Further east in the Indian region (00-02 LT) F-layer descended with very low $\mathrm{f}_{\mathrm{o}} \mathrm{F} 2$ values at Thumba, near dip equator and there was no spread-F during the night. There was no echo seen for some time in the pre-sunrise period. The F-layer descent with low $\mathrm{f}_{\mathrm{o}} \mathrm{F} 2$ values and no echo condition for some time were also noticed at Sri Harikota and Waltair located away from the dip equator. Very strong sporadic-E with several multiples was seen both at Sri Harikota (00150330 LT) and Waltair (0100-0345 LT). These are associated with the large prompt penetration westward electric field in the night-side. Finally at
Kwajalein the electric field is westward as indicated by absence of equatorial type of sporadic-E during 07-09 LT on 10 November and also very high values of $\mathrm{f}_{\mathrm{o}} \mathrm{F} 2$ at $09 \mathrm{LT}$ (no development of ionization anomaly).

\section{Conclusion}

An abnormally large increase of the flow pressure of the solar wind and large southward Interplanetary Magnetic Field from 1850 to 2100 UT on 9 November 2004 caused an abnormally large equatorial prompt penetration dawn to dusk electric field.

In the American longitude sectors, the F-region over Jicamarca $\left(75^{\circ} \mathrm{W}\right)$ and Sao Luis $\left(44^{\circ} \mathrm{W}\right)$ was lifted upward, broken into two portions and the upper one was blown out of the range of the ionosonde. At Fortaleza near the edge of electrojet, the F-region lifted up but did not go outside the range of ionosonde.

Further east at Ascension Island $\left(14.4^{\circ} \mathrm{W}\right)$, the event is in the evening hours and the F-region was lifted up from 1800 to 1915 LT without any deformation. It descended rapidly at $1930 \mathrm{LT}$ due to the reversal of electric field polarity.

At Indian stations $\left(77^{\circ}-83^{\circ} \mathrm{E}\right)$ Trivandrum, near dip equator and Waltair (dip $22.7^{\circ} \mathrm{N}$ ) the F-region was pushed down and later disappeared, as a consequence of enhanced westward ionospheric electric field in the night sector. The ionosonde did not receive any echo for couple of hours untill the next sunrise. Strong sporadic-E with multiple traces was seen both at SHAR and Waltair during the night of 10 November and appears to be associated with the unusual large westward electric field imposed in the equatorial region in the night-side Indian sector.

Further east, the F region at Kototaban (03$05 \mathrm{LT})$, Indonesia also disappeared after a rapid descend. At Kwajalein (05-07 LT) the westward equatorial electric field resulted in the absence of equatorial type of sporadic-E from 07-09 LT and high value of $f_{o} F 2$ in the absence of the development of ionization anomaly.

\section{References}

Abdu M A 1997 Major phenomena of the equatorial ionosphere-thermosphere system under disturbed conditions; J. Atmos. Sol. Terr. Phys. 59 1505-1519.

Abdu M A, Maruyama T, Batista I S, Saito S and Nakamura M 2007 Ionospheric response to the October 2003 superstorm: Longitude/local time effects over the equatorial, low and middle latitudes; J. Geophys. Res. 112 A10306, doi: 10.1029/2006JA012228. 
Abdu M A, de Paula E R, Batista I S, Reinisch B W, Matsuoka M T, Camargo P O, Vetiz O, Denardine C M, Sobral J H A, Kherani E A and de Siqueira P M 2008 Abnormal evening vertical plasma drift and effects on ESF and EIA over Brazil-South Atlantic sector during the 30 October 2003 Superstorm; J. Geophys. Res. 113 A07313, doi: 10.1029/2007JA012844.

Bagia M S, Iyer $\mathrm{K} N$, Joshi $H$, Thampi $S \mathrm{~V}$, Tsugawa T, Ravindran S, Sridharan R and Pathan B M 2011 Low-latitude ionospheric-thermospheric response to storm time electrodynamical coupling between high and low latitudes; J. Geophys. Res. 116 A01303, doi: 10.1029/2010JA015845.

Basu S, Basu Su, Groves K M, Yeh H C, Su S-Y, Rich F J, Sultan P J and Keskinen M J 2001a Response of the equatorial ionosphere in the South Atlantic region to the great magnetic storm of July 15, 2000; Geophys. Res. Lett. 28 3577-3580.

Basu Su, Basu S, Valladares C E, Yeh H C, Su S Y, Mackenzie E, Sultan P J, Aarons J, Rich F J, Doherty J P, Groves R M and Bullet T W 2001b Ionospheric effects of major magnetic storms during the International Space Weather Period of September and October 1999: GPS observations VHF/UHF installations and in situ density structures at middle and equatorial latitudes; J. Geophys. Res. 106 30,389-30,413.

Blanc M and Richmond A D 1980 The ionospheric disturbance dynamo; J. Geophys. Res. 85 16691688.

Chandra H and Rastogi R G 1971 General features of the ionosphere at Thumba; J. Inst. Telecom. Engrs. 14 $207-216$.

Chandra H and Rastogi R G 1974 Diffuse type and blanketing type sporadic-E at Kodaikanal; Curr. Sci. 43 $533-535$.

Dashora N and Pandey R 2007 Variations in the total electron content near the crest of the equatorial ionization anomaly during the November 2004 geomagnetic storm; Earth Planet. Space 59 127-131.

de Jesus R, Sahai Y, Guarnieri F L, Fagundes P R, de Abreu A J, Becker-Guedes F, Brunini C, Gende M, Cintra T M F, de Souza V A, Pillat V G and Lima W L C 2010 The ionospheric F-region in the South American sector during the intense geomagnetic storm of 14 December 2006; Adv. Space Res. 46 909-920.

Fejer B G 2004 In: Auroral phenomena and solar-terresstrial relations, CAWSES handbook -1 (eds) L M Zelling, M A Geller and J H Allen, Boulder, CO.

Fejer B G, Gonzales C A, Farley D T, Kelly M C and Woodman R F 1979 Equatorial electric fields during magnetically disturbed conditions: 1 . Effect of the interplanetary magnetic field; J. Geophys. Res. 84 5797-5813.

Fejer B G, Jensen J W, Kikuchi T, Abdu M A and Chau J L 2007 Equatorial ionospheric electric fields during the November 2004 magnetic storm; J. Geophys. Res. 112 A10304, doi: 10.1029/2007JA012376.

Fuller-Rowell T J, Millward G H, Richmond A D and Codrescu M V 2002 Storm-time changes in the upper atmosphere at low latitude; J. Atmos. Sol. Terr. Phys. 64 13831391.

Kelley M C 1989 The Earth's ionosphere, Plasma Physics and Electrodynamics, Academic, San Diego, California.

Kelley M C, Fejer B G and Gonzales C A 1979 An explanation for anomalous ionospheric electric field associated with a northward turning of the interplanetary magnetic field; Geophys. Res. Lett. 6 301-304.

Kil H and Paxton L J 2006 Ionospheric disturbance during the magnetic storm of 15 July 2000: Role of the fountain effect and plasma bubbles for the formation of large equatorial plasma bubbles for the formation of large equatorial plasma density depletions; J. Geophys. Res. 111 A12311, doi: 1029/2006JA011742.

Kikuchi T H, Luhr T, Kitamura T, Saka O and Schliegel K 1996 Direct penetration of the polar electric field to the equator during a DP2 event as detected by the auroral and equatorial magnetometer chains and the EISCAT radar; J. Geophys. Res. 101 17,161-17,173.

Mannucci A J, Tsuratani B T, Abdu M A, Gonzales W D, Komjathy A, Echer E, Lijima B A, Crowley G and Anderson D 2008 Superposed analysis of the dayside ionosphere response to four geomagnetic storms; J. Geophys. Res. 113 A00A02, doi: 10.1029/2007JA012732.

Maruyama T 2006 Extreme enhancement in total electron content after sunset on 8 November 2004 and its connection with storm enhanced density; Geophys. Res. Lett. 33 L20111, doi: 10.1029/2006GL027367.

Maruyama T, Richmond A D, Fuller-Rowell T J, Codrescu M V, Sazykin S, Toffoletto F R, Spiro R W and Millward G H 2005 Interaction between direct penetration and disturbance dynamo electric fields in the storm-time equatorial ionosphere; Geophys. Res. Lett. 32 L17105, doi: 10.1029/2005GL023763.

Nishida A 1968 Coherence of geomagnetic DP2 fluctuations with interplanetary magnetic variations; J. Geophys. Res. 73 5549-5559, doi: 10.1029/JA07i017.

Rajaram G, Das A C and Rastogi R G 1971 Ionospheric Fregion disturbances and their possible mechanisms; Ann. Geophys. 27 469-475.

Rastogi R G 1989 The equatorial electrojet: Magnetic and ionospheric effects, In: Geomagnetism (ed.) Jacobs J, Academic Press, 3 461-525.

Rastogi R G and Chandra H 1974 Interplanetary magnetic field and the equatorial Ionosphere; J. Atmos. Terres. Phys. 36(2) 377-379.

Rastogi R G and Chandra H 1999 Geomagnetic and ionospheric research; In: Space Research in India: Accomplishments and Prospects (eds) M S Narayanan, Hari Om Vats, B Manikiam, H Chandra and S P Gupta, PRL Alumni Association, pp. 99-135.

Rastogi R G and Patel V L 1975 Effect of interplanetary magnetic field on the ionosphere over the magnetic equator; Proc. Indian Acad. Sci. A82 121-141.

Rastogi R G, Chandra H and Chakravarty S C 1971 The disappearance of equatorial Es and the reversal of electrojet current; Proc. Indian Acad. Sci. A74 62-67.

Rastogi R G, Chandra H, Sharma R P and Rajaram G 1972 Ground based measurements of ionosphere phenomena associated with the equatorial electrojet; Indian J. Radio. Space Phys. 1 119-135.

Sastri J H, Niranjan K and Subbarao K S V 2002 Response of the equatorial ionosphere in the Indian (midnight) sector to the severe magnetic storm of July 15, 2000; Geophys. Res. Lett. 29, doi: 10.1029/2002GL015133.

Tulasi Ram S, Rama Rao P V S, Prasad D S V V D, Niranjan K, Gopi Krishna S, Sridharan R and Ravindran S 2008 Local time dependent response of postsunset ESF during geomagnetic storms; J. Geophys. Res. 113 A07310, doi: 10.1029/2007JA012922.

Vasyliunas V 1972 The inter-relationship of magnetospheric processes; In: Earth's magnetiospheric processes (ed.) McCormack B M (New York: Springer), pp. 29-38.

Veenadhari B S, Alex S A, Kikuchi T, Shinhori, Singh A R and Chandrasekhar E 2010 Penetration of magnetospheric electric field to the equator and their effects on the low latitude ionosphere during intense geomagnetic storms; J. Geophys. Res. 115 A03305, doi: 1029/2009JAO14562. 
Yermolaev Yu I, Kuznetsov V D, Chertok I M, Panasyuk M I, Myagkova I N, Zhitnik I A, Kuzin S V, Eselevich V G, Bogod V M, Arkhanagelskaja I V, Arkhangelsky A I and Kotov Yu D 2008 Magnetic storm of November 2004: Solar, interplanetary and magnetospheric disturbances; J. Atmos. Sol. Terr. Phys. 70 334-341.

MS received 22 December 2011; revised 18 May 2012; accepted 7 June 2012 